\title{
Las Estructuras Polares en la Obra de José Martí y Julián del Casal
}

I.

A Cuba le cupo el honor de producir dos de los más ínclitos poetas moCasal (1863-1893). ${ }^{1}$ En el bienio de $1962-1963$ se festejarán sendas fechas significativas en la vida y la obra de ambos creadores, antagónicos por su modo de enfocar la realidad, pero afines por su búsqueda y elaboración de formas renovadas del lenguaje literario español. El presente año de 1962 marca el octogésimo aniversario del florecimiento de la gran prosa martiana, de la publicación del Ismaelillo, y de la composición de la mayor parte de sus Versos libres, ${ }^{2}$ y, por consiguiente de la iniciación del modernismo en el verso. La fecha inicial auténtica es I882 tan sagazmente señalada por Federico de Onís. ${ }^{3}$ En ${ }^{1963}$ se celebrará el centenario del nacimiento de $\mathrm{El}$ Conde de Camors, espíritu refinado en cuerpo endeble, $y$, como su coterráneo Martí, destinado a morir prematuramente. Para contribuir a la conmemoración de la doble fecha se ha escrito este análisis de una peculiar modalidad estilistica muy prodigada en la creación poética de ambos bardos.

Casal fue, en las palabras de José María Monner Sans, el primer modernista de formación cubana." Su vida triste en el empodrecido am-

1 Véase el ensayo de Pedro Henríquez Ureña, "El modernismo en la poesía cubana" en Ensayos criticos (México: Fondo de Cultura Económica, 1960), pp. 17-22. En la p. 18 sostiene la idea, cronológicamente inexacta, de que hay cuatro iniciadores del modernismo: Casal, Martí, Darío y Nájera.

2 Se suele dar 1882 como fecha de estos versos, aunque según Martí algunos fueron escritos en 1878 .

3 En su Antología de la poesía española e bispanoamericana (Nueva York: Las Américas, 1961).

Julián del Casal y el modernismo bispanoamericano (México: El Colegio de México, 1952), p. 118. 
biente cultural de la colonia ${ }^{5}$ constituye un factor determinante en el desarrollo de su visión sombría, pues no cabe duda que esta "alma solitaria en medio de la estepa de la vida"," sufría de un agudo sentimiento de soledad en un medio horro de alta cultura, según una de sus muchas autocaracterizaciones. Martí, en cambio, sólo pasó lus años adolescentes en el suelo natal, condenado a ser, a partir de 1871 , un errante en busca de un país de libertad. No obstante este exilio prolongado, para hacer la historia ideológica y literaria del Maestro es indispensable tomar en cuenta sus estudios en Cuba con Rafael María de Mendive y los meses de martirio en el presidio político cubano - experiencia ésta dolorosa, pero clave en la formación de las ideas y la moral martianas. Martí y Casal, entonces, pese a su común origen cubano, son dos modernistas de signo contrario, fenómeno señalado con precisión por Cintio Vitier:

Si Martí encarna entre nosotros las nupcias del espíritu con la realidad, con la naturaleza y con la tierra misma, Julián del Casal... significa todo lo contratio. Su incapacidad radical para asumir la realidad, que unas veces interpreta como signo de "idealismo", de pureza y anhelo inconciliables con lo mezquino de la circunstancia, y otras, las más, como fatal "impotencia" de su ser, se resuelve en un estado de ánimo dominante: el hastío.7

La actitud de los dos poetas frente a la realidad circundante los separa profundamente; Martí, para usar las palabras de Vitier, representa las nupcias con la realidad, mientras que Casal revela una arraigada ineptitud para hacerle frente y aceptarla tal como era. La vida de Casal fue estática: permaneció en la raquítica atmósfera de la colonia ("Si partiera / al instante yo quisiera / regresar" ${ }^{8}$ ) con excepción del malogrado

5 Casal no valora el ambiente donde vive con mucha generosidad. En Bustos declara que Varona ofrece "el caso singular de haber llegado a ser un gran escritor en un medio propicio para realizar toda clase de empresas, menos para las intelectuales... ama verdaderamente su Ideal, amor que no ha visto justipreciado por su pueblo, porque no teniendo èste más que el de la vida material, difícil le sería comprender que un individuo pueda perseguir otro más noble, más elevado, más inmaterial". [Bustos y Rimas (La Habana: Imprenta La Moderna, 1893), p. 32].

6 "Al juez supremo", Poesías completas, ed. Mario Cabrera Saqui (La Habana: Dirección de Cultura, 1945), p. 199. A menos que se indique lo contrario, de aquí en adelante todas las citas de la poesía de Casal serán de esta edición. Por consiguiente, sólo se indicará el título seguido de la página o las páginas que corresponden a esta edición.

7 Lo cubano en la poesía (Santa Clara: Universidad Central de las Villas, 1958), p. 242.

8 "Nostalgias", p. 222. 
viaje corto a España; la de Martí, dinámica: se alejó de un ámbito donde "las letras sólo pueden ser enlutadas o hetairas"9 porque faltaba allí la libertad.

A despecho de la disparidad en la Weltanschauung de estas dos figuras capitales del modernismo, en su obra se manifiestan semejanzas estilísticas en suficiente número para tesistir la calificación de fortuitas. Limitándonos al fenómeno de las estructuras polares, Martí y Casal se sirvieron de construcciones antinómicas cuya naturaleza revela cabalmente el mundo poético de cada uno. Este mundo existencial se concretiza en un fondo común de técnicas y tropos, probando una vez más la consanguinidad literaria de los modernistas, cuyo arte es el producto de elementos abrevados en idénticas o similares fuentes - europeas en su mayoría-, pero asimilados y plasmados después en un estilo novador. ${ }^{10}$ Es el propósito de este estudio deslindar una de las constantes de la estilistica modernista - la construcción antitética - en la obra de estos dos bardos, desçubrir su raíz sociológica y señalar sus valores estéticos.

En la obra de Casal ${ }^{11}$ las construcciones antitéticas suelen caracterizarse por una visión dualística, por una polaridad que no admite, sino en instantes raros, el contrapeso de la síntesis. Para entender estas estructuras y evaluarlas cumplidamente hay que tener en cuenta que Casal fracasó en su intento de adaptarse a "su circunstanicia", y, procuró fugarse o evadirse de ella. Su mundo fantástico — su realidad-chocaba con el ambiente circundante y este encuentro de valores contradictorios se tradujo en estructuras antitéticas, producto del hastío y el pesimismo:

Así mi ensueño, pájaro canoro de níveas plumas y rosado pico, al querer en el mundo hallar cabida,

encontró de lo real los muros de oro

9 José Martí en su necrología "Julián del Casal", Obras completas (La Habana: Lex, 1948), I, 822.

10 A diferencia del caso de otros modernistas, en el de Martí y Casal es difícil aducir el hecho de una influencia mutua. Martí habia leído los "versos tristes y joyantes" de su coterráneo, y había expresado su reservada admiración por ellos en la crónica publicada en 1893 en Patria a raíz de la muerte de Casal [Obras completas (La Habana: Lex, 1948), I, 822-823] ¿Conoció Casal las obras martianas? No lo sabemos a ciencia cierta, pero es probable que alcanzó a leer Ismaielillo, Versos sencillos y algo de la prosa.

11. Nos ocuparemos principalmente de la poesía de Casal, en vista de que no hay todavía una edición completa de la prosa, dispersa, en su mayor parte, en revistas y periódicos. 
y deshecho, cual frágil abanico, cayó entre el fango inmundo de la vida.

("Mi ensueño", p. 230)

Las expresiones de fuga, falseamiento y aislamiento se convirtieron en norma poética y vital. Para sobrevivir en la sociedad habanera, Casal, según Gustavo Duplessis, se vio obligado a fingir, pues "el éxito mundano y la creciente fama literaria van enseñando a Julián cuán necesaria resulta a veces la pose para que las gentes vulgares comiencen a tomar en serio a un escritor". Ia Desgraciadamente la pose y la evasión se trocaron en su única verdad valedera, y desde la torre de marfil el mundo a su alrededor le parecía un eterno conflicto entre su realidad subjetiva y la desconcertante y desengañadora atmósfera objetiva que lo aprisionaba.

Martí también advirtió la presencia de fuerzas contrarias en la existencia:

Los hombres van en dos bandos: los que aman y fundan, los que odian y deshacen. Y la pelea del mundo viene a ser la de la dualidad hindú: bien contra mal. ${ }^{13}$

Pero intentaba efectuar una síntesis, una relación armónica, buscando transformar la realidad crasa y materialista en materia noble:
Alas nacet vi en los hombros
de las mujeres hermosas:
$Y$ salir de los escombros,
Volando las mariposas. (4I:5I)

En énfasis sobre la transformación que observamos en éstos y otros muchos versos martianos es la secuela, en parte, de la misión redentora que rigió su vida (nótese en la prosa arriba citada el predominio de los vocablos de acción: bandos, fundan, pelea; y de la ética: aman, bien contra mal), y creó en él la necesidad de ver el aspecto optimista, positivo e

12 "Julián del Casal", Revista Bimestre Cubana, LIV (1944), 54.

13 Obras completas (La Habana: 'Trópico, 1936-1953), X, 143. En adelante, al referimos a esta edición, lo haremos en forma abreviada. Usaremos números arábigos para indicar el volumen y la página; se indicará primero el volumen, y luego la página, separando con dos puntos las respectivas cifras. 
ideal de la existencia humana. A Casal le faltaba tal dimensión heroica, siendo el arte lo único que orientaba su existencia. De ahí su actitud de apartamiento y conflicto ante el cariz repugnante de la vida, mientras que Martí insistía en la necesidad de luchar para el mejoramiento del hombre y acrecentar el margen de belleza y de virtud en la tierra.

\section{II.}

De los dos modernistas cubanos, Martí es el único que nos dejó un cuerpo nutrido de ideas teóricas que arrojan luz sobre sus procedimientos estilísticos; de Casal, hasta la fecha, sólo poseemos cortos fragmentos de sus conceptos estéticos. Uno de estos trozos, alusivo al tema de la polaridad, aparece en un cuento que vio la luz en La Habana Elegante correspondiente al to de agosto de $\mathrm{I} 890$, "El primer pesar":

Después de haber visto una verdadera hermosura, se quedaba aletargado, como el que toma una fuerte dosis de morfina, sin que la carne participara de tal estado de ánimo que le imposibilitaba para hacer otra cosa que soñar. Todo lo contrario le ocurría a la vista de las mujeres de baja condición social. Delante de ellas, una agitación intensa despertaba sus sentidos, excitándolos hasta la congestión, porque la ley del contraste es la única que domina ciertos temperamentos, por más exquisitos y delicados que sean. En los últimos vástagos como Armando Morel, de una familia de raza fina, nerviosa y degenerada, suelen manifestarse siempre tan inexplicables preferencias. (El subrayado es mío) ${ }^{116}$

Además de sugerir explicaciones a los problemas sicológicos y emocionales de Casal - pues el personaje Armando Morel es, sin duda, el alter ego del poeta- estas líneas revelan la preocupación casaliana con los contrastes de la vida. Igual interés, expresado a través de una cadena de símiles, se encuentra un año más tarde en un estudio sobre Rubén Darío publicado en La Habana Literaria:

A pesar de las luchas sostenidas en los primeros días, por alcanzar la celebridad, el alma del escritor se ha conservado igual. Salió esplendorosa de ellas, como el iris del diamante de la negrura del

14 Reproducido por Gustavo Duplessis, op. cit., pp. 50-51. 
carbón, como el fuego de la estrella de la tiniebla de la noche, como la nieve del lirio de la humedad del pantano, como el oro de la cabellera de la palidez del cráneo, como la púrpura de la sangre de la inmundicia del organismo, sin perder su frescura, su pureza, su idealidad. ${ }^{15}$

En esta pluralidad de antinomias el énfasis cae sobre el miembro idealista de la antítesis, procedimiento de filiación transformista, pues se trata de una configuración que expresa un desplazamiento hacia una forma de realidad más elevada ${ }^{16}$ : iris del diamante $<$ negrura del carbón: fuego de la estrella < tiniebla de la noche; nieve del lirio < bumedad del pantano; oro de la cabellera < palidez del cráneo; puirpura de la sangre < inmundicia del organismo. Al final, Casal subraya lo ideal con el resumen trimembre de forma sustantival: frescura, pureza, idealidad. En la estilística de Casal lo transformista es de aparición escasa; en cambio, en el estilo martiano es un rasgo característico. De hecho, el lector familiarizado con los giros del Apóstol notará la semejanza de las cons-

15 Ibid., p. 266.

16 A veces el proceso transformista de la imaginería polar es de signo contrario, orientación totalmente en consonancia con la visión sombría y solitaria de Casal:

Siempre el destino mi labor humilla

o en males deja mi ambición trocada:

donde arroja mi mano una semilla

brota luego una flor emponzoñada.

(La cursiva es mía)

("Nihilismo", p. 252)

En otras ocasiones el énfasis cae sobre lo ideal, y el poeta emite pensamientos de forma y fondo martianos:

Yo te busqué en el fondo de las almas

que el mal no ha mancillado

y surgen del estiércol de la vida

cual lirios de un pantano.

(La cursiva es mía)

("A la Belleza", p. 248)

Nótese en estos últimas versos la doble antítesis: estiércol de la vida $\mathrm{x}$ livios de un pantano, y la polaridad interior del último miembro: lirios $\mathrm{x}$ pantano. La yuxtaposición de los contrarios resulta más dramática así, y, a la vez, indica la proximidad y lucha de las fuerzas antitéticas. 
trucciones arriba citadas con las de Martí, fenómeno que iremos señalando a lo largo de este ensayo. ${ }^{17}$

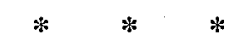

La antítesis casaliana es una constante, presente en las composiciones primigenias, lo mismo que en las expresiones maduras. No pretendemos llevar a cabo un estudio sistemático de las fuentes e influencias relacionadas con este procedimiento formal, pesquisa que resultaría ardua amén de infructuosa, dada la manera individual y original de absorber múltiples fuentes literarias entre los escritores modernistas. Por consiguiente no elucidaremos la harto conocida raíz romántica de la antítesis; en cambio, sí quisiéramos detenernos a considerar, aunque en forma breve, la sorprendente consanguinidad literaria de Baudelaire y Casal, ${ }^{18}$ las polaridades bodelerianas, y la ascendencia del francés sobre el cubano. ${ }^{19}$

Los dos son poetas de signo sincrético; Baudelaire representa el nexo entre la poesía tradicional y moderna de Francia mientras que Casal armoniza rasgos del romanticismo, parnasismo y simbolismo en un estilo cromático, plástico y musical. Como Casal, que anuncia una nueva estética sin desligarse del romanticismo, ${ }^{20}$ Baudelaire efectuó una aproximación de corrientes literarias aparentemente contradictorias. El poeta mago, descubridor de senderos desconocidos en el verso, se identificó con el romanticismo de cuyo influjo, como en el caso de Casal, no se libraron sus creaciones. Sin embargo, Baudelaire entendió la estética ro-

17 Véase como ejemplo este trozo martiano:

Tiene en los hombres nuevos la idea viva una crudeza ingenua $\mathrm{y}$ hermosa que viene a ser, en la defensa fuerte de la verdad humana, como en poesía la crudeza épica, y sale del alma natural y ardiente como la nuez de oro de las entrañas del monte. Cual verá la arruga, o el grano de tierra; cual verá el oro. $(11: 233-234)$.

is Sobre este tema véanse los Capítulos V y VI del ya citado estudio de José María Monner Sans.

19. Baudelaire, cuyos versos utiliza para epígrafe (de Rimas), es, según Casal, "el más grande poeta de nuestros tiempos..." [Bustos y rimas, ed. cit., p. 41].

220 Rufino Blanco-Fombona define así la presencia de modalidades e inclinaciones estéticas de índole opuesta en la obra de Casal: "Romántico por temperamento y parnasiano por anhelo de perfección formal... une en sus poemas la sensibilidad de un emotivo con la destreza de un cincelador de filipéndulas de oro". Al comentar el poema "Flores" observa el mismo crítico: ¡Cuántas estigmas del romanticismo se advierte ahí! El vaso de alabastro, la adelfa, la virgen anémica, el corazón, la plegaria, la antítesis entre la oración y la blasfemia. iY el cantarse a sí mismo! [El modernismo y los poetas modernistas (Madrid: Mundo Latino, 1929), pp. 87-887. 
mántica en su sentido más lato, es decir, depurada de todo exceso retórico y sentimental:

Qui dit romantisme dit art moderne, - c'est-à-dire intimité, spiritualité, couleur, aspiration vers l'infini, exprimées par tous les moyens que contiennent les arts. ${ }^{21}$

Las dualidades humanas le fascinaron al poète mandit lo mismo que al bardo cubano. En Mon coeur mis à mu el poeta francés expresó los siguientes conceptos alusivos al tema:

Il y a dans tout homme, à toute heure, deux postulations simultanées, l'une vers Dieu, l'autre vers Satan. L'invocation à Dieu, ou spiritualité, est un désir de monter en grade; celle de Satan, ou animalité, est une joie de descendre.22

La proclividad hacia lo antitético - "ley de los contrastes" de Casal-se manifestó temprano en la vida del poeta de Les fleurs du mal, según confesión propia en el arriba citado escrito: "Tout enfant, j'ai senti dans mon coeur des sentiments contradictoires; l'horreur de la vie et l'extase de la vie". ${ }^{23}$ La antinomia - borreur, extase - la tendencia a verlo todo en forma de contraste, se transparenta en su obra lo mismo que en sus declaraciones íntimas o teóricas. Lo curioso es, sin embargo, que en los versos de Baudelaire tropezamos con frecuencia con la misma imagineria que Casal utiliza en sus estructuras antitéticas. La huella bodeleriana en Casal se nota en los "motivos de inspiración", y también en "ciertos intermitentes y deseados prosaísmos, cierta inclinación a lo nauseabundo, lo horrendo y lo macabro... [que] le llegan de aquel Baudelaire que transformó el fango de la vida en áureas joyas poéticas: "Tu m'as donné ta boue et j'en ai fait de l'or." ${ }^{2}$ Este es sólo uno de los versos que parecen indicar una influencia más que fortuita del bardo francés sobre el cubano. Limitando nuestra discusión del tema a la polaridad y a la ima-

21 Oeuvres (París: La Pleiade, 1932), II, 66-67. Para un estudio comparativo, más bien histórico que estilístico, de la relación de Baudelaire con la estética romántica y los artistas del romanticismo, véase André Ferran, L'estbétique de Baudelaire (París: Hachette, 1933), pp. 73-118. De especial valor sobre el mismo tema es el libro de Henri Peyre, Connaissance de Baudelaire ('París: José Corti, 1951), pp. 184-190.

22 Oeuvres, ed. cit., II, 647.

23 Ibíd., II, 663.

24 Monner Sans, op. cit., p. 73. 
ginería utilizada en las construcciones antitéticas, son significativos los. versos que a continuación citamos porque en ellos abundan tropos quemás adelante estudiaremos como claves de la antítesis casaliana: crapands, marécage, limaçons:

Une odeur de tombeau dans les ténèbres nage, Et mon pied peureux froisse, au bord du marécage Des crapauds imprévus et de froids limaçons. ${ }^{2 \sigma}$

En otra ocasión una doble polaridad traduce el conflicto del poeta: " $O$ fangeuse grandeur! sublime ignominie!" 26

Idéntica enfermedad de "spleen et idéal", concretizada en construcciones análogas, aparece en la obra de Casal. Ya en $1887^{27}$ en "Desolación" se patentiza el sentimiento de vacuidad y hastío en versos de filiación romántica que terminan con una confrontación polar - blasfemiaplegaria:

Ningún monje sombrio, solitario, arrebujado en su capucha oscura, póstrase a orar, con místico deseo; y ha tiempo no resuena en el santuario ni la plegaria de la joven pura, ni la blasfemia horrible del ateo.

(p. 104)

En las líneas de "Desolación" se evidencia la presencia de "la ley del contraste", producto en parte de la herencia libresca del romanticismopero, a la vez, de aquel perenne dolor de cuyo peso se quejaba Casal en. más de una ocasión:

Libre de abrumadoras ambiciones, soporto de la vida el rudo fardo, porque me alienta el formidable orgullo

25 "Le Coucher du soleil romantique", Les fleurs du mal (París: Louis: Conard, 1922), p. 247.

${ }_{26}$ "Spleen et Idéal" (XXV), Les fleurs du mal, ed. cit., p. 44.

27 Esta es la fecha que fija Gustavo Duplessis en su ya citado estudio. "Julián del Casal", p. 73. 
de vivir, ni envidioso, ni envidiado, persiguiendo fantásticas visiones, mientras se arrastran otros por el fango

para extraer un átamo de oro del fondo pestilente de un pantano.

("Autobiografía", p. 56)

La yuxtaposición del "rudo fardo" y las "fantásticas visiones" evoca tres imágenes claves del metaforismo antitético: átamo de oro, portador de lo noble y hermoso, fango y pantano, símbolos de materialismo, ${ }^{28}$ de "la mezquina realidad" ("El arte", p. 94).

La base de las construcciones antitéticas de Casal es un núcleo de tropos materialistas, símbolos constantes de su poética: pantano, miasma, cieno, abismo, lodazal, fango; a estos tropos el poeta contrapone un símbolo de filiación idealista para completar la estructura. La característica espacial de los tropos recurrentes empleados en estos "pareados" apunta siempre hacia una realidad baja, de signo negativo a pesar del miembro idealista de la configuración, pues la visión de Casal es eminentemente pesimista:20

Ansia de perfección mi ser consume, aunque me rindo en lodazal infecto, como al hallar un lirio sin perfume desfallece entre abrojos el insecto.

("Esquivez", p. 292)

28 En sus "bustos" Casal prodiga similareș símbolos materialistas para describir la realidad. De Garibaldi dice: "el alma más grande, después de la de Jesús, que ha surgido del estercolero de la humanidad..." (p. 20). La carrera del doctor Esteban Borrero Echevarría le evoca este sintagma de genuino sabor martiano: "Su pensamiento anhelaba ascender en pos de las águilas hacia el sol y tuvo que marchar tras los reptiles hacia el lodazal (p. 67). Y, por fin, una construcción arquetípica de la dicotomía noética de Casal: "Firme [José Fornaris] en sus convicciones, marchaba sereno, por el camino de la vida, sin hundirse en el lodo, porque le guiaba el Ideal..." (p. 109). [Bustos y rimas, ed. cit.].

29 Arrojan luz sobre la melancolía casaliana estas líneas alusivas al tema que forma parte del "busto" de Juana Borrero:

La melancolía que destilan las primeras producciones de ciertos artistas no es más que la fermentación de los pesares que, día por día, les ha causado la observación de las múltiples deficiencias que la vida ofrece ante sus deseos. No es imaginaria, como algunos pretenden, sino real... Los que se consuelan en algunas horas, son los que se construyen, en el campo de 
El lodazal infecto es el mundo en que el solitario y hastiado joven Casal espera, de un momento a otro, exhalar su último aliento; lirio, con el modificante sin perfume y abrojos sugieren la fealdad y la oquedad del ambiente. Cieno, forma sinónima de lodazal, se combina con el verbo bajar en los versos siguientes, revelando de nuevo el carácter espacial de nivel ínfimo a que aludimos arriba:

Joven, desde el azul de tu idealismo, viste al cieno bajar tus ilusiones, como se ve en bandadas a los alciones caer ensangrentados al abismo. ${ }^{30}$

\section{(“O Altitudo!", p. 267)}

El azul, símbolo cromático del país de ensueño y uno de los colores predilectos de los modernistas, se contrasta con el cieno adonde van a dar las ilusiones; los últimos dos versos subrayan el sentimiento de desencanto con el verbo descendente - caer-y el adjetivo ensangrentados.

En otra composición fango y el verbo caer concretizan sentimientos análogos, el hastío y la aniquilación:
Así mi ensueño, pájaro canoro
de níveas plumas y rosado pico,
al querer en el mundo hallar cabida.
encontró de lo real los muros de oro

la fantasía, un lazareto ideal, donde esconden la purulencia de sus llagas, pero donde nadie los seguirá por temor a los contagios mortales. Alli viven con sus ensueños, con sus alucinaciones y con una familia compuesta de seres imaginarios. Cada vez que salen al mundo, el asco los obliga a volver sobre sus pasos... Tan absoluta desconformidad, no sólo los hastía de lo que han conocido, sino de lo que no han visto, de lo que no verán jamás.

[Bustos y rimas, ed. cit., pp. 83-85]

30 Otra manifestación del tropo cieno se da en el poema autobiográfico "Flor de cieno" (p. 200). "En él Casal se imagina fresca pasionaria que crece en el cieno de urna cineraria. Sirviéndose de contrastes cromáticos de valor simbólico el poeta retrata su olímpico aislamiento:

tho ven [los hombres] que, como planta siempre verde, entre el negro raudal de $\mathrm{mi}$ amargura guarda mi corazón su esencia pura. 
y deshecho, cual frágil abanico, cayó entre el fango inmundo ${ }^{3 t}$ de la vida.

("Mi ensueño", p. 230) 32

Queda por mencionar otra de las imágenes recurrentes de las construcciones antitéticas, de particular significación debido al lugar central que ocupa en la tropología martiana: mariposa. Esta figura etérea aparece en los versos siguientes donde se repiten las características de la construcción antitética ya perfiladas: el idealismo representado espacialmente por lo empíreo (mariposa, cuya nobleza está intensificada con blanca); el pantano, estrato ínfimo de la existencia humana donde se estrellan y se ahogan los valores puros, y, por fin, el empleo de un vocablo descendente, sugeridor de lo imposible-sumergida:

y mi alma noble, soñadora y franca, está por tu pasión envilecida, como ligera mariposa blanca en pantano de sangre sumergida.

("A Berta", p. II8) 33

El tormento amoroso y sus problemas congéneres, más bien que un conflicto con el ambiente, se expresa en los arriba citados versos. La mariposa, al igual que en la obra de Martí, portadora de un mundo ideal,

31 El adjetivo "inmundo" lo utiliza Casal en otra ocasión, pero en combinación con cieno, en un poema de filiación parnasiana "Paisaje de verano". la intención es estética, pero aun en estos versos plásticos que a continuación citamos, no desaparece la sombra melancólica:

Polvo y moscas. Atmósfera plomiza donde retumba el tabletear del trueno y. como cisnes entre inmundo cieno, nubes blancas en cielo de ceniza.

[p. 2267

32 Véase "Colón en la Rábida" (p. 341) donde utiliza Casal muy parecido conjunto imaginístico: fétidos miasmas, fondo cenagoso del pantano, y el verbo caer.

33 Semejante construcción imaginística, pero con una intención noética contraria, es decir, idealista, se encuentra en "A la Belleza" de Rimas (p. 248) donde Casal utiliza estiércol de la vida en lugar de pantano de sangre y lirios de un pantano en lugar de mariposa blanca. Véase también el "busto" de Bonifacio Byrne, Bustos y rimas, ed. cit., p. 96 , donde se clarifica el plano real de pantano. 
de ensueño, choca con un realismo cruel. En otras composiciones Casal dará a sus ideas y emociones la forma concreta de negras mariposas para caracterizar la pérdida de la nobleza e idealidad:
Ahí van mis versos, Negras mariposas nacidas en el campo de mis sueños, no guardan ni el aroma de las rosas que libaron en días más risueños.

$$
\text { ("Madrigal", p. II } 2)^{34}
$$

La negra mariposa no es el único caso del color simbólico; al contratio, abundan las estructuras cromáticas, y, como era de esperar, predominan los tonos sombrios que evocan pensamientos melancólicos y tétricos en el lector. El matiz oscuro, casi siempre el negro, lo contrasta Casal con colores que simbolizan lo positivo, noble e ideal: blondo, azul, blanco, amarillo, dorado. Es significativo que en los conjuntos cromáticos persista el patrón ya observado de la figura del pájaro o del insecto alado, encarnaciones ambas del ansia del poeta de librarse de las amarras terrenales y hallar solaz en las regiones etéreas. En "Al juez supremo" las negras mariposas de "Madrigal" se truecan en aves negras (forma adjetival bisémica empleada por el poeta para describir sus creaciones "mórbidas"), y hacen juego de contrapunto con espigas blondas:

No arrancó la Ambición las quejas hondas ni el Orgullo inspiró los anatemas que atraviesan mis mórbidos poemas cual aves negras entre espigas blondas.

$$
\text { (p. } 199)^{35}
$$

34 Otro poema en que aparece la misma imagen con idéntico plano real se titula "Album femenino: Corina Rowland y del Monte", p. 333. La mariposa negra hace aparición en la tropología martiana también, aunque con valor tico:

El hombre libre sin la frente cargada de esas mariposas negras de la vida: -responsabilidad, aislamiento del alma, labor innoble, desaliento--, triscador y alegre, descuidado y genial, fresco y dueño de sí propio, llena comúnmente - sin conciencia del antro que le atrae- el alma solitaria, o el cuerpo ocioso, que acepten sus miradas vagabundas $[73: 1597$.

35 Compárese este trozo desglosado de Amistad funesta donde Martí se sirve de ave negra para representar a la veleidosa y celosa Lucía: 
Siguiendo un módulo muy repetido, Casal, a través del vaticinio paternal, ve su infortunio como sino ineludible entre la alegría de los demás hombres. Pero no lucha contra su destino; sus ansias e inquictudes se confrontan pasivamente con un mundo hostil (negros $\mathrm{x} a z u l$ ):

Como pájaros negros por azul lago, nublaron sus pupilas mil pensamientos, $y$, al morir ẹn la sombra su acento vago, vi pasar por su mente temordimientos como pájaros negros por azul lago.

("Recuerdo de la Infancia", p. 266)

Otro pareado cromático, rosa $\mathrm{x}$ negro, lo emplea Casal en el poema que describe su breve encuentro con Darío en La Habana (I892), al dirigirse el nicaragüense a España en calidad de enviado diplomático de su patria a la fiesta conmemorativa del cuarto centenario del descubrimiento de América. De aquel corto contacto nació "Páginas de vida", cuyo cromatismo se distingue por la ausencia del modificante, y el uso; en cambio, del sustantivo:

Si hubiéramos más tiempo juntos vivido nos nos fuera la ausencia tan dolorosa. ¿Tú cultivas tus males, yo el mío olvido! ¡Tú lo ves todo en negro, yo todo en rosa!

(p. 281)

El oro y el negro se contrastan en los versos siguientes que reflejarz un momento inusitado de inquietud política; en forma alegórica y cromática presenta Casal la amenaza para Cuba representada por España y los Estados Unidos:

hay dos aves de rapiña contemplando sus destellos:

una de plumaje áureo, otra de plumaje negro.

...al influjo del aire que agitaban sus compañeras con los abanicos, [Lucía] volvió a abrir los ojos, que parecían turbios, como si hubiera cruzado por su pensamiento un ave negra. [25:91]. 
Viendo la perla romperse entre su concha de cieno, ya afilan los corvos picos, para alcanzar sus fragmentos.

("La perla", p. I38)

Si en los versos anteriores los colores áureo, negro tienen un valor noético totalmente arbitrario, y, por ende, alegórico, en el rótulo de "Versos azules" se manifiesta un cromatismo de filiación catacréstica y simbólica. Estos versos "azules" dedicados a Ina Lasson, evocan un cuadro de belleza plástica cuya perfección está sugerida en el color cerúleo del título. El procedimiento antitético sirve para crear un retablo, a la manera de la escuela parnasiana, en que la hermosura de la Lasson está perfilada contra un fondo de claridad - nítida camelia, rosado de la aurora:

Hay en tu seno en que el temor habita, Cual negro insecto en nítida camelia, no el valor infantil de Margarita sî la incesante agitación de Ofelia.

Porque al oír tu voz, amante y tierna, la tristeza del alma se evapora, cual la sombra de lóbrega caverna al resplandor rosado de la aurora.

Influido por el parnasismo, sobre todo en Nieve, Casal ha dejado varios. poemas en que une la técnica antitética al arte plástico parnasiano; la intención en tales composiciones es estética, y la polaridad sirve para intensificar el cuadro:

Noche de primavera, Solitario, como rosa amarilla en manto negro, destácase ya el disco de la Luna en la negrura azul del firmamento, y hasta la Tierra, en dilatados haces, 
envía sus purísimos reflejos

("Las Oceánidas", p. I47) 36

De valor plástico y cromático, pero con una intención que trasciende los límites de lo puramente estético, son las líneas siguientes en las cuales Casal ofrece un conjunto antitético de estructura geométrica;

A través de esas composiciones, el alma de la niña [Juana Borrero] parece un botón de rosa amortajado en un crispón, un ramo de violetas agonizante entre la nieve, un disco de estrella sumergido en un lago turbio. ${ }^{37}$

Vinculado a la estética parnasiana, sobre todo en cuanto ésta aplicaba procedimientos pictóricos al arte literario, es el pareado luz x sombra, aunque en la variante del conjunto en los siguientes versos se notan caracteristicas románticas también. En la primera estrofa el bardo contrapone sombra y luminosos baces; sol y oscuro firmamento; en la segunda, tormenta, reposo:

¡Oh, Señor!, si la sombra no deshaces

y en mi alma arrojas luminosos haces,

como un sol en oscuro firmamento,

haz que sienta en mi espiritu moroso

primero la tormenta que el reposo,

primero que el hastío... jel sufrimiento!

("Oración", p. 300)

Luz y sombra como figura compuesta, pasan al título del poema ${ }^{38}$ a que los versos citados abajo pertenecen:

36 Para otros ejemplos de una construcción antitética dentro de un poema parnasiano, véanse "La canción del torero" (p. 121), y "Una maja" (p. 183) donde Casal se entusiasma ante el sensualismo de la maja cuya castañeta surge "cual mariposa negra de entre el granizo".

37 Bustos y rimas, ed. cit., p. 86.

38 En su versión original de 1886. Con ligeras variantes aparece en la edición de Cabrera Saqui con el rótulo "Tras la ventana" (p. 68). 
Y cuando el áureo sol de otra mañana, rompiendo de la noche el negro manto, vino a herir el cristal de mi ventana, evaporóse en mi mejilla el llanto que me arrancó del alma aquella escena $\tan$ triste $y \tan$ hermosa, que aun su recuerdo llena de luz y sombra mi alma tenebrosa.

("Tras la ventana", p. 68)

En la estilistica antitética de Casal, además de los aspectos ya esclarecidos, descuellan varias técnicas de especial interés. Entre ellas figura la de dar en serie los componentes de dos mundos opuestos, separando las realidades en pugna en estrofas independientes. Tal construcción caracteriza el poema "Blanco y negro"; Casal se sirve en él de valores cromáticos para recalcar su visión pesimista de la existencia. Pero el cromatismo lo combina con figuras y verbos de parejo valor noético, realzando así el plano real de los dos orbes representados respectivamente por blanco y negro:

Sonrisas de las vírgenes difuntas

en ataúd de blanco terciopelo recamado de oro; manos juntas que os eleváis hacia el azul del cielo como lirios de carne; tocas blancas de pálidas novicias absorbidas por los ensueños celestiales; francas tisas de niños rubios; despedidas que envían los ancianos moribundos a los seres queridos; arreboles de los finos celajes errabundos por las ondas del éter; tornasoles que ostentan en sus alas las palomas al volar hacia el Sol; verdes palmeras de los desiertos africanos; gomas árabes en que duermen las quimeras; miradas de los pálidos dementes hacia las flores del jardín; crespones 
con que se ocultan sus nevadas frentes

las vírgenes; enjambres de ilusiones color de rosa que en su seno encierra el alma que no hirió la desventura; arrebatadme al punto de la Tierra, que estoy enfermo y solo y fatigado, y deseo volar hacia la altura, porque allí debe estar lo que yo he amado.

El conjunto imaginístico blanco, oro, azul, lirios, tocas blancas, pálidas novicias, celestiales, rubios, éter, alas, palomas, volar, verdes palmeras, pálidos, flores, nevadas, color de rosa, altura, todo sugiere un plano noético y emocional de perfección, pureza, ternura, en breve, ideal. Lirios, alas, palomas, volar, palmeras, flores, altura, constituyen, por su carácter de encumbramiento y elevación, un mundo simbólico de signo positivo. Lo negativo se presenta en contraria serie de tropos, en la parte "negra" del poema: témpanos de bielo, entrañas, bidra de Lerna, líquida caverna, devorar, segasteis, vientos tempestuosos, afilados colmillos, bienas, malezas, cuervos, balas, ciervos, pesadillas, fiebre. La nota alicaida aparece al final, cuando el poeta, que comprende lo imposible de su visión ideal, se queja y pide:

despedazad mi ser atormentado que cayó de las célicas regiones y devolvedme al seno de la nada...

Los dos estratos espaciales -el empírico y el ínfimo- concretizan la posición ambivalente de Casal; deseo de huir (cílicas regiones) y la intuición de que está frente a un laberinto, de que está atrapado (devolvedme al seno de la nada) (Pp. 2Ir-2I2).

Idéntico procedimiento antitético se utiliza en "Cuerpo y alma", de título bipartito como "Blanco y negro". El poeta evoca las cualidades del cuerpo primero, y luego, en la segunda sección, las del alma, utilizando un esquema estructural análogo al de "Blanco y negro", el cual se caracteriza por una serie o acumulación de imágenes de forma sustantival, seguida del verbo al final de la oración:

Sonrisas de...

manos juntas que... 
tocas blancas de...

francas risas de. .. etc.

arrebatadme al punto de la Tierra...

En "Cuerpo y alma", Casal se muestra más atrevido en su imagineria, sobre todo en la primera sección donde echa mano de tropos de filiación bodeleriana y decadentista, a saber: viscoso, como la baba, estéril, como los senos, ardor genital, inflamados sus vellones, cenagoso manantial. A diferencia de "Blanco y negro" en la estructura de "Cuerpo y alma" Casal utiliza el adjetivo al comienzo de cada sintagma en lugar del sustantivo:

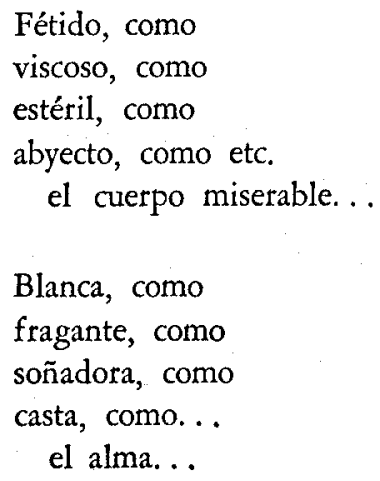

En el envio del poema pide el bardo permanente solaz, petición que dirige al Señor en una estructura antitética de filiación transformista, re* veladora del perenne deseo casaliano de evadirse del mundo cotidiano:
purifica mi carne corrompida
o, librando mi alma, de mi cuerpo,
bas que suba a perderse en lo infinito,
cual fragante vapor de lago infecto. ${ }^{39}$

(El subrayado es mío)

39 La queja del hombre que se siente incapaz de triunfar sobre la dureza de la vida, se da también en Martí en momentos de desilusión y pesimismo. La dualidad de la interrogación martiana en los versos siguientes se asemeja al imperativo bipartito de Casal: 
Y, en los últimos versos, expresa metafóricamente una antinomia de lamento y demanda: "que la alondra no viva junto al tigre, / que la rosa no viva junto al cerdo" 40 (pp. 3II-3I3).

Resumiendo los puntos elucidados en la segunda sección de este estudio, la antítesis casaliana nace de una pugna entre realidad y sueño; como el hijo salvaje que se duerme en el desierto, Casal,

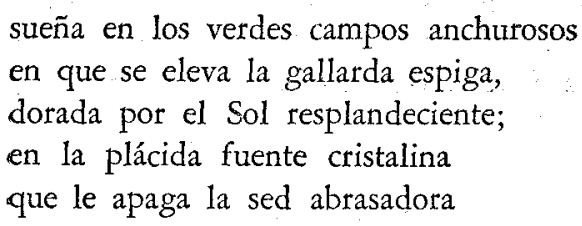

Pero, su sed de idealismo y de belleza, como en el caso del hijo salvaje, no se trocaton en realidad:

Pero al salir del sueño venturoso sólo ve, dilatadas las pupilas, desierto, el arenal ilimitado: roja, la inmensa bóveda vacía.

("El sueño en el desierto", p. I05)

III.

Las polaridades martianas se manifiestan con la misma insistencia que las casalianas, pero se diferencian de éstas en dos sentidos: revisten más variadas encarnaciones, $y$, además de un origen síquico tienen una

... ¿a qué me dieron

Para vivir en un tigral, sedosa

Ala, y no garra aguda? o por acaso

Es ley que el tigre de alas se alimente?

[41:185]

40 Véanse también los once tercetos de "En el campo" (pp. 304-305) donde presenta el poeta conceptos en pugna en cada estrofa, y "Flores" (p. 213) cuya polaridad consiste en una encarnación imaginística desarrollada en dos estrofas independientes: una azucena blanca: la plegaria x una adelfa púrpura: la blasfemia. 
fuente filosófica, moral y política. El ingrediente ideológico es de capital importancia en la antítesis martiana, porque el Maestro, sin merecer el calificativo de filósofo sistemático, es un hombre de ideas, dimensión que le falta a Casal, y, que en la imaginería de Martí se refleja en los tropos que nacen de los aspectos polares de su epistemología; de un lado, monte, águila, ala, luz, estrella, antorcha, copa, oro, y del otro, abismo, buitre, yugo, carbón, uña, cerdo, antro, fango, para mencionar sólo los más recurrentes. Estos símbolos ideales y materialistas patentizan las aparentes contradicciones de las ideas martianas, contradicciones, que sometidas al análisis se desvanecen, porque de ellas construye Martí una síntesis universal. Vivía en una época en que el legado del romanticismo y del positivismo sedujo a los hombres, y, como observa Jorge Mañach, Martí, entre ellos, cayó bajo la férula de ambos:

Es un romántico por la sensibilidad, por el anhelo de absolutos, por la sobrevaloración de lo espiritual, por la tendencia a proyectar la intimidad del yo sobre la realidad externa, por la confianza en la bondad innata del hombre y el optimismo mesiánico que de ella se deriva. Pero todo ese tomanticismo está frenado, equilibrado en Martí por la conciencia vivísima del sentido objetivo y científico en que su siglo reaccionaba a los excesos anteriores del entusiasmo y de la fantasía.

Martí está hecho de "ala" y también de "raíz", para aludir a sus palabras favoritas. Generado en la fuga ideal del romanticismo, su pensamiento se repliega sobre lo concreto y cotidiano; su absolutismo se ensancha para acoger lo relativo; acomódase en él lo espiritual a lo sensible, y el optimismo ensoñador se modera de cautelas realistas. ${ }^{41}$

Estas dos corrientes filosóficas - Romanticismo, Positivismo-son más que una herencia libresca; en la vida de Martí representan actitudes vitales, pues su idealismo, apasionamiento, su fe en la "bondad innata del hombre", en la posibilidad de llevar a cabo tareas aparentemente imposibles de realizar, son proyecciones de su misión política y redentora. Pero, al mismo tiempo, en la visión total de Martí hay una perspicacia - se diría, casi una clarividencia- que le hizo ver con ojos de realidad, con los pies en la tierra, todos los problemas de la organización del Partido Revolucionario Cubano, y, en un sentido más amplio, todos los pro-

41 "Ala y raíz", Arcbivo José Martí, 9 (1945), 163. 
blemas de Cuba y de la América hispánica: educacionales, políticos, literarios, sociales, raciales, económicos, etc. Martí tuvo conciencia de la herencia filosófica que regía su existencia, al igual que la de sus compatriotas americanos, y, en la siguiente antinomia expresó el dilema del hombre decimonónico de la América española: ". . hemos venido, a pujo de brazo, a nuestra América de hoy, heroica y trabajadora a la vez, franca y vigilante, con Bolívar de un brazo y Herbert Spencer de otro" (2 r:209). A "nuestra América" y a Cuba en especial, consagró Martí su vida; su decisión de sacrificarse, de entregarse cuerpo y alma a la tarea revolucionaria, moldeó sus ideas estéticas, y, su estilística. Su empeño revolucionario lo llevó a la lucha por la dignificación y elevación del hombre, y, de allí, en sus configuraciones antitéticas, el énfasis sobre la elevación. ${ }^{42}$ Pero, siendo al mismo tiempo realista, lo empíreo está compensado con una figura de menor vuelo cuya añadidura resulta en la estructura polar.

En la evolución de esta estructura los temas de la soledad y el aislamiento son de fundamental significación en el caso de Martí como en el de Casal. Pero, la necesidad y la capacidad martianas de creer en el hombre - "el hombre es feo, pero la humanidad es hermosa" - impide el desarrollo de una actitud de hastío y soledad intensos. Sin embargo, los momentos de desengaño, no tan raros en Martí como se suele pensar, ${ }^{43}$ producen estructuras dualísticas sin la nota transformista o sintética, como en los versos siguientes de "Copa ciclópea":

\section{Al niño triscador, al venturoso}

142 Alfredo A. Roggiano define la postura de Martí, poeta frente a los problemas sociales:

...poeta de la acción, no podía quedar en la mera contemplación del pai. saje o de los acontecimientos del mundo, ni menos ser un sibarita de poses más o menos angustiadas o falsamente nihilistas. El hombre es un "deber vivo", un deber de construir y de crear, de ser y de ayudar a ser. Su poesía no podía encerrarse en las torres de marfil. ["Poética y estilo de José Marti", Humanitas, I, (1953), 366].

43 La tormenta interior de su alma está resumida en estos sintagmas fragmentarios de filiación polar:

YO [sic]: esto es: Una personalidad briosa e impotente, libérrima y esclava, nobilísima y miserable, - divina y humanísima, delicada y grosera, noche y luz. Esto soy yo. Esto es cada alma. [Apuntes inéditos (La Habana: Publicaciones del Archivo Nacional, 1951), p. 45].

Véase el capítulo intitulado "Desengaños" del Esquema ideológico de José Martí; ed. Manuel Pedro González e Ivan A. Schulman (México: Cultura, 1961), pp. 445-455. 
De alma tibia y mediocre, a la fragante

Mujer que con los ojos desmayados

Abrirse ve en el aire extrañas rosas,

Iris la Tierra es, roto en colores

Raudal que juvenece y rueda limpio

Por perfumado llano, y al retozo

$Y$ al desmayo después plácido brinda!

Y para mí, porque a los hombres amo

$\mathrm{Y}$ mi gusto $\mathrm{y}$ mi bien terco descuido,

La Tierra melancólica aparece

Sobre mi frente que la vida bate

De lúgubre color inmenso yugo!

La frente encorvo, el cuello manso inclino,

$\mathrm{Y}$, con los labios apretados, muero.

$(4 I: I 30)$

En estos desgarradores versos el poeta expresa un abandono próximo al de Casal, y, el sentimiento de soledad se plasma en una estructura dualística: la felicidad del mundo x la desventura personal:

Yo he vivido poco; pero tengo miedo de vivir y sé lo que es, porque veo a los vivos. Me parece que todos están manchados, y en cuanto alcanzan a ver un hombre puro; empiezan a correrle detrás para llenarle la túnica de manchas. La verdad es que yo que quiero mucho a los hombres, vivo huyendo de ellos. Siento a veces una melancolía dolorosa (La cursiva es mía) (25:98).

Pero, hay una trascendente distinción entre la soledad de los dos modernistas cubanos; Casal sufre como consecuencia de su incapacidad de adaptarse a su sociedad; Martí, en cambio, quiere ayudar a la sociedad, formar parte de ella, pero los hombres no siempre lo entienden, y lo rechazan por entrometido, hipócrita o fantaseador. "Todo el que lleva luz se queda solo" (4I:I36), afirmó Martí, y, si moría de soledad, ésta nacía de un amor abundante y desinteresado: " $\mathrm{Oh}$ verso amigo, / Muero de soledad, de amor me muero!" (41:120).44

Grosso modo, las variedades de estructuras antitéticas de la estilís-

44 Sobre, la soledad como fuente de una visión polar que a su vez se refleja estilísticamente en construcciones antitéticas véase también "Isla famosa" (41:138). 
tica martiana se reducen a tres: las de transformación, las de dos mundos opuestos y estáticos (similares a las casalianas), y, las construcciones compuestas o sintetizadas. Las primeras se caracterizan por el empleo de un símbolo de profundidad y otra de altura con el énfasis sobre la transformación hacia el tropo de filiación idealista del juego simbólico, reflejando de esta manera la preocupación martiana por el encumbramiento del ser humano y su sociedad:

La mente, contagiada del hábito común de jeremiar, dice: - "iLo que no está en la tierra!"--El juicio sólido, dice: Inaplicación de fuerza rebosante:- inactividad de mente activa. ¡Hormiga que lleva en el vientre huevos de águila! (62:105)

La segunda variante se manifiesta en estructuras como la siguiente en que no hay ningún intento por efectuar una transición:

La vida humana está harta, como la tierra, de montes y de llanos. ¡Y a las veces de criptas siniestras y de abismos! $Y$ es fuerza a cada paso sacar los ojos de los montes, que son los hombres altos, $y$ ponerlos en llanuras (28:165).

$Y$, por fin, la tercera estructura donde opera el principio de la armonía que pervade tantos escritos martianos. Refiriéndose a su estética expone Martí su doctrina equilibrada en los versos siguientes:

...Acá un torrente:

Aquí una piedra seca. Allá un dorado

Pájaro, que en las ramas verdes brilla,

Como una marañuela entre esmeraldas-

Acá la huella fétida y viscosa

De un gusano: los ojos dos burbujas

De fango, pardo el vientre, craso, inmundo.

Por sobre el árbol más arriba, sola

En el cielo de acero una segura

Estrella; y a los pies el horno,

El horno a cuyo ardor la tierra cuece-

Así ha de ser la noble poesía:

Así como la vida: estrella y gozque; 
La cueva dentellada por el fuego,

El pino en cuyas ramas olorosas

A la luz de la luna canta un nido,

Canta un nido a la lumbre de la luna.

$(43: 15-16)$

Torrente, pájaro dorado y estrella son los tropos de valor positivo, que sugieren la fecundidad, elegancia e idealidad de la poesía, y son contrapesados por formas polares: piedra seca, gusano. Pero no pretende el poeta efectuar una síntesis: el gozque y la estrella son dos elementos: imprescindibles de la creación. Entre los vocablos que Martí utiliza para sugerir el materialismo encontramos dos de particular trascendencia porque son tropos recurrentes de la polaridad casaliana: fango, fétido. $\mathrm{Y}$, por pertenecer al léxico de ambos artistas ilustran lo que constituye el propósito de este estudio: dilucidar las similitudes de vocabulario, imaginería y técnicas estilísticas en lo que se refiere a la polaridad de Martí y Casal, sin pretensión de agotar las manifestaciones de este fenómeno formal en la obra martiana.45

Las coincidencias en las construcciones antitéticas de Casal y Martí comienzan con los términos de bajeza, materialismo y realismo que en ambos modernistas son análogos en muchos instantes. El mundo de valores crasos está expresado con los tropos fango, gozque, serpiente y cocodrilo:

Empieza el hombre en fango y para en ala.

$\mathrm{Y}$ a su paso triunfal, los maculados,

Los viles, los cobardes, los vencidos,

Como serpientes, como gozques, como

Cocodrilos de doble dentadura

De acá, de allá, del árbol que le ampara,

Del suelo que le tiene, del arroyo

Donde apaga la sed, del yunque mismo

Donde se forja el pan, le ladran y echan

El diente al pie, al rostro el polvo y lodo,

Cuanto cegarle puede en su camino.

$(43: 15-16)$

445 Véase la primera sección del Capítulo III de mi libro Símbolo y color en la obra de José Martí (Madrid: Gredos, 1960) para un estudio más pormenorizado al respecto. 
Pero, a diferencia de Cașal quien no vislumbra un mundo real mejorado, sino un mundo ideal evadido, Martí, como en el primer verso arriba citado - "Empieza... en fango y para en ala"- afirma su fe en la transformación del hombre. Pero la labor revolucionaria cansa y debilita. El mal entendido y asediado Apóstol confiesa en más de una ocasión su soledad y dolor, fuente éste de su arte: "Yo soy como aquellos llanos de Siberia, que dan fruto abundante en medio del frío.-Del dolor, flores" (62:128). Como compensación de una vida atribulada busca febrilmente un mundo de contornos ideales donde vivir en paz. También Martí se evade - con frecuencia en su poesía, que para él es una especie de bálsamo-, pero su huida no es más que pasajera, un instante de reposo y de consuelo en la lucha humana a la cual vuelve con renovado brío. De ahí que en la construcción bipartita de "Flores del "cielo" donde el bardo da expresión a su angustia, no separa el mundo superior que pinta de los hombres ("De mis ojos, del mundo a que van Ilenos, / Ríos de luz sobre los hombres rueden!"). Pero, lo que es imperfecto en la vida lo evoca con los tonos sombríos que recuerdan los de Casal:

¿Flores? No quiero flores! Las del cielo Quisiera yo segar!

........ en mi alma sacian

Su hambre [las sierpes], y asoman a la cueva lóbrega

Donde mora mi espíritu, su negra

Cabeza, y boca roja y sonriente!

(El subrayado es mío)

De la dualidad humana, en lugar de sus componentes abismales, el poeita escoge el orbe idealista para su morada:

\section{Surjan}

Donde mis brazos alas, y parezca

Que al ascender por la solemne atmósfera,

De mis ojos, del mundo a que van llenos,

Ríos de luz sobre los hombres rueden!

De lumbre astral, en mi jardín, el cielo, 
Un ramo haré magnífico de estrellas.

¡No temblará de asir la luz mi mano!

(El subrayado es mío) (4r:129)

Alas, hiz, cielo, estrellas, el adjetivo astral, el verbo ascender representan el empeño martiano por asir lo ideal, dejando tras sí raudal de luz. Martí no se rinde ante el mundo materialista del abismo, la cueva o el pantano a modo de Casal; su labor de reformador y su moral nunca le permitieron cejar en la faena de enaltecer y mejorar. Asi es que el abismo martiano está acompañado de su contrapeso, y, en él, es decir, en lo ideal y noble, descubre Martí la morada del artista y de todo hombre superior ("hombre montañoso" lo llamaba):

Hay montañas al lado de los abismos, y al lado de los decaimientos, fortalezas: el cariño y el entusiasmo miran siempre al cielo, y nosotros vemos al poeta, no en el abismo cuyo examen desdeñamos, sino en la montaña que presencia nuestra admiración (El subrayado es mío) (50:190-I9I).

A través de la antinomia abismo x montaña presenta Martí la raíz ética de su filosofía, sobre todo en el sintagma no en el abismo cuyo examen desdeñamos. En éste, amén de otros juegos antitéticos, Martí "suele contraponer lo malo a lo bello, para que la elección quede clara".46

Además de los elementos morales, de indudable relevancia en la génesis de las estructuras polares, es significativo el concepto de la gran cadena de vida, concepto predominante de la filosofía trascendentalista de Emerson a quien Martí leyó y admiró. Es patente en los escritos martianos la idea emersoniana de que de lo ínfimo se asciende ${ }^{47}$ (pensamiento de oriundez neoplatónica también), y que de las cumbres es capaz el hombre de examinar las dualidades de la existencia, pero con particular ahinco en la transformación de lo inmundo a lo noble, a lo ascensional:

46 Enrique Anderson Imbert, "La prosa poética de José Martí; A propósito de Amistad funesta", en Memoria del Congreso de Escritores Martianos (La Habana, 1953), p. 583.

47 Emerson se refiere a "spires of form" (espirales de la forma) en su poema "Nature" Complete Works (ed. del centenario; Boston y Nueva York: Houghton Mifflin, 1903), IX, 281. 
.......... Yo he visto un grano

Arrojado al azar, trocarse luego

En brillante haz de fuego

Para orgullo del pueblo americano.-

$\mathrm{Y}$ de un tronco tendido

En mitad del camino, mal herido

Surgir la vida bajo forma nueva

Que en forma de brillantes mariposas

Al cortejar a las fragantes rosas

Del muerto tronco el vivo espíritu lleva;

En estos versos fragmentarios expone Martí una filosofía transformista y trascendentalista que recibe una encarnación más lírica y acabada en los Versos sencillos ["Y salir de los escombros / Volando las mariposas; / y todo como el diamante, / Antes que la luz es carbón" / (4I:5I)], y en prosa, en las líneas que a continuación citamos, en las cuales se sirve Martí de una imagen empleada repetidas veces en la obra de Casal: estiércol:

. . así como en lo animal salva al hombre de la epidemia la misma sustancia que la produce, así de sus llagas morales, estiércol del camino que se convierte en mariposa, surge el remedio que las cura $(35:$ I22).

Sinónimo de estiércol es otro tropo de profundidad, materialista, que Martí prodiga, aunque menos que Casal-fango;

Los hombres parecen estatuas de oro que juegan con fango. Tienen celos unos de otros, y con el ruido que hacen sus querellas, no se oyen las voces pacíficas del ejército de sabios (22:160).

Este comentario decepcionado sobre el hombre que malgasta sus valiosas dotes (estatuas de oro) en fruslerías indignas de su potencia (juegan con fango) lo inspiró la visita a una exposición de electricidad en Nueva York (I893). La intención docente de la crónica sobre los últimos adelantos eléctricos se refleja en el corto trozo arriba citado donde la construcción polar subraya la futilidad y frivolidad humanas. 
En la tropología martiana se dan otros ejemplos de la combinación fango-oro $0^{48}$ o de variantes como fango $>$ seno de la luz (18:67), oro < entrañas ( 1 i:233-234). En las líneas siguientes se patentiza la nota transformista tan repetida en las estructuras martianas, rasgo estilístico que imparte un valor antagónico al fango martiano, comparado con el casaliano. Martí no se detiene, en actitud lastimera, ante lo inicuo de la vida, pues de lo fétido moldea lo fructuoso, lo sano, lo puro, lo bello: 49

Todo tiene la entraña fea y sangrienta: es fango en las artesas el oro en que el artista talla luego sus joyas maravillosas; de lo fétido de la vida saca almíbar la fruta y colores la flor; nace el hombre del dolor y la tiniebla del seno maternal, y del alarido y el desgarramiento sublime; $y$ las fuetzas magnificas y corrientes de fuego que en el horno del sol se precipitan y confunden, no parecen de lejos a los ojos humanos sino manchas! (9:I6I).

Pasando ahora a los elementos cromáticos de las estructuras antitéticas, observamos en ellas la riqueza de la paleta martiana $y$, a la vez algunas combinaciones construidas a base de lo negro como las casalianas:

Yo pienso, cuando me alegro

Como un escolar sencillo,

En el canario amarillo,-

Que tiene el ojo tan negro!

48 Véase como ejemplo esta serie fragmentaria:

Dorar el fango.

Flor blanca de listas de sangre.

El cerdo: o el caballo. [73:46]

49 Este valor noético del miembro materialista del juego antitético está implícito en un pareado donde usa Martí una forma sinónima de fango-podredumbre $>l u z$, y las estructuras antagónicas yuxtapuestas: cerdo $>$ llamas azu . les; carbón $>$ diamante:

De la podredumbre misma sale la luz: el cerdo corrompido echa llamas azules. Como la fiera es el espíritu del hombre, en que es más fina la que se cría entre las ásperas y agrias; o como los poetas ingleses, que por la misma negrura de su cielo, buscan en su fantasía púrpuras de puesta de sol y tintes celestes; o como el monte de carbón, que da el diamante. [39:128] 
La yuxtaposición de amarillo y negro sugiere la imposibilidad de la alegría, de lo ideal, sin sus cualidades polares. En el comentario de valor autobiográfico que a continuación ofrecemos, la visión es, como en los versos antes citados, dualística pero sintética; es un cuadro compuesto de alegrías y tristezas, de sacrificios y recompensas:

En un ave de dos alas

Bogo por el cielo azul:

Un ala del ave es negra

Otra de oro Caribú.

Dentro de la corriente parnasiana cabe el siguiente pareado en el cual emplea Martí plata como variante de blanco para sugerir cualidades de elegancia y refinamiento además de pureza:

Franjas de plata en terciopelo negro adornan el sencillo catafalco [del presidente Garfield]. Así ha de ser la muerte cuando se ha vivido bien, luego de la vida: en negro terciopelo, franja de plata! (I6:88).

Las estructuras antitéticas de Martí son legión, pero para el propósito de este estudio sólo hemos entresacado aquellas relacionadas con las casalianas. Siguiendo este criterio, quisiéramos concluir con la comparación de un poema de Casal, "En el campo", y las secciones II y III de los Versos sencillos de Martí. El cotejo de estos versos revelará un procedimiento técnico similar, es dcir, la confrontación de los com. ponentes de orbes polares en las sendas series de estrofas, seguida de la elección del poeta de aquello que más concuerda con su Weltanschauung. "En el campo" revela la ascendencia bodeleriana -amén de la de otros poetas decadentes- sobre las ideas de Casal, pues el bardo cubano siempre prefiere a lo natural, lo que emana de un paraíso artificial:

Tengo el impuro amor de las ciudades, y a este sol que ilumina las edades prefiero yo del gas las claridades. A mis sentidos lánguidos arroba, más que el olor de un bosque de caoba, el ambiente enfermizo de una alcoba. 
En las nueve estrofas restantes de la composición, la estructura antitética es idéntica, es decir, la preferencia de Casal cae sobre el segundo miembro del conjunto, siendo lo único que varía, el verbo conectivo entre los dos estratos contropuestos:

Estrofa

$\begin{array}{lll}\text { III selvas tropicales } & \text { plácenme } & \text { sombríos arrabales } \\ \text { IV la flor... en el } & & \\ \text { sendero } & \text { olvido por } & \text { la flor de invernadero } \\ \text { V la voz del pája- } & & \text { la música de una rima } \\ \text { ro } & \text { anima } & \text { etc. (pp. 304-305). }\end{array}$

En los versos martianos también abunda el personalismo, "la tendencia $x$ proyectar la intimidad del yo sobre la realidad externa" 50 pero Martí, a diferencia de Casal, contrasta elementos de una experiencia más profunda y universal:
Yo sé de Egipto y Nigricia, $Y$ de Persia y Xenophonte;
$Y$ prefiero la caricia
Del aire fresco del monte.
Yo sér1 las historias viejas
Del hombre y de sus rencillas;
$Y$ prefiero las abejas
Volando en las campanillas.

Martí prefiere la riqueza natural que para él es una especie de bálsamo que cicatriza las heridas infligidas por la hipocresía y la maldad humanas; en la naturaleza se repone de las fatigas y los desengaños. Reduciendo a un esquema la visión martiana de los restantes versos pertinentes de Versos sencillos, veremos que el Maestro siempre elige lo que es natural y puro. La técnica antitética es la misma de "En el campo", perolos valores noéticos son totalmente contrarios - caso de una antítesis diametralmente opuesta a la de Casal:

50 Jorge Mañach, "Ala y raíz", p. 163.

51 Hemos tomado la libertad de suprimir la "de" después de "sé" para conservar el octosílabo. V. p. 284, n. 25 de la reciente edición de la poesía martiana: Versos, ed. Eugenio Florit (Nueva York: Las Américas Publishing Co., 1962). Florit también omite la preposición. 


\begin{tabular}{|c|c|c|}
\hline $\begin{array}{l}\text { máscara y vicio } \\
\text { del corredor de } \mathrm{mi} \\
\text { hotel }\end{array}$ & me vuelvo & $\begin{array}{l}\text { manso bullicio } \\
\text { de mi monte de lau- } \\
\text { rel }\end{array}$ \\
\hline el arroyo & me complace más & el mar \\
\hline el oro tierno & denme & el bosque \\
\hline $\begin{array}{l}\text { el oro hecho tierra } \\
\text { Barbullendo en la }\end{array}$ & prefiero estar & en la sierra \\
\hline redoma & & $\begin{array}{l}\text { cuando vuela una palo- } \\
\text { ma } \\
(4 \mathrm{x}: 54-55)\end{array}$ \\
\hline
\end{tabular}

El estudio comparativo de estas dos composiciones poéticas, a más de revelar intrigantes coincidencias estilísticas, sirve para comprobar la idea que planteamos al principio de este ensayo, es decir, que Martí y Casal utilizan recursos formales, análogos o idénticos en ciertos casos, pero cada uno, a su modo. Las discrepancias en el empleo de una técnica dada son tan relevantes como las similitudes, puesto que el estudio de las diferencias nos aproxima al mundo artístico y existencial de ambos artistas cuyo complejo filosófico, ideológico, sicológico y emocional se concretiza en los giros estilísticos. Sin tocar la cuestión crenológica, sino en forma breve, el estudio de las estructuras antitéticas revela el fondo común de técnicas, vocabulario e imaginería de que los modernistas se valieron, contribuyendo con su arte novador a la renovación de la expresión literaria hispánica decimonónica. Con Federico de Onís decimos que los modernistas se definen "por la unidad de su personalidad, y todos juntos por el hecho de haber iniciado una literatura independiente..."52 Así nuestros dos bardos; persiguieron formas expresivas que tradujeron adecuadamente su mundo emotivo y noético. La construcción polar, con sus facetas cromáticas y tropológicas, era sólo uno de múltiples procedimientos dilectos de ambos modernistas. En ella vertieron sus contrariedades, aspiraciones y ensueños; su estructura bipartita sirvió cabalmente para representar el destino del artista, morador temporal, pero sufrido de un mundo materialista y hostil.

IVAN A. SCHULMAN

Wasbington University

$31-\mathrm{X}-62$

52 "La poesía hispanoamericana", Cuadernos (Paris), 21 (1956), 17. 